Published by Al-Nahrain College of Medicine P-ISSN 1681-6579

E-ISSN 2224-4719

Email: iraqijms@colmed-alnahrain.edu.iq

http://www.colmed-alnahrain.edu.iq

http://www.iraqijms.net

Iraqi JMS 2020; Vol. 18(1)

\title{
Evaluation of Autophagy Flux LC3 Gene Expression and Serum IFN- $\gamma$ in Pulmonary Tuberculosis Patients
}

\author{
Sarah A. Wahwah ${ }^{1} P h D$, Thanaa R. Abdulrahman ${ }^{2} P h D$, Ahmed A. Mankhi ${ }^{3} P h D$ \\ ${ }^{1}$ Dept. of Pharmacy, Al zahrawi University College, Karbala, Iraq, ${ }^{2}$ Dept. of Microbiology, College of Medicine, Al- \\ Nahrain University, Baghdad, Iraq, ${ }^{3}$ National Reference Laboratory (NRL) of Tuberculosis Respiratory, Baghdad Medical \\ City, Baghdad, Iraq
}

\section{Abstract}

Background Mycobacterium tuberculosis (Mtb) is the major causal pathogen of human tuberculosis (TB). Autophagy is a highly conserved cytosolic pathway influencing the immune responses and the elimination of intracellular pathogens including Mtb.

Objective To evaluate the effect of Mtb on autophagy flux with autophagy related genes of LC3I and LC3II, beside the evaluation of serum interferon-gamma (IFN- $\gamma$ ) level in patients with pulmonary TB.

Methods A total of 50 blood samples were collected from patients with pulmonary TB, besides 30 as healthy control. The real-time polymerase chain reaction (PCR) method was determined the measuring of mRNA expression of autophagy-related genes of LC3I and LC3II. Serum IFN- $\gamma$ protein concentration was measured using sandwich Enzyme Linked ImmunoSorbant assay.

Results The present study showed an increasing in LC3-I level in newly-diagnosed pulmonary TB patients rather than in the control group despite statistically non-significant $P>0.05$, while LC3-II showed decreasing in all pulmonary TB groups but statistically non-significant $P>0.05$. Autophagy flux ratio of LC3-I and LC3-II genes showed a statistically significant decrease in pulmonary TB groups especially in newly- diagnosed $(p$ value $=0.02$ ) rather than control groups. Moreover, the study of the serum level of IFN $-\gamma$ showed an increase in the level of IFN $-\gamma$ with $p=0.0001$ in pulmonary TB patients in comparison with the control group. In addition, the correlation between autophagyrelated genes and IFN- $\gamma$ have been shown a positive significant correlation ( $p$ value $=0.013$ ) in the multidrug-resistant (MDR) TB group.

Conclusion Autophagy flux ratio showed a statistically significant decrease in pulmonary TB groups particularly in newly-diagnosed TB patients rather than control groups, this indicates the different modulation factors that may affect the process of autophagy. The only positive correlation within biomarkers of the present study has been shown that LC3-II is a dependent factor on IFN- $\gamma$ in MDR group.

Keywords
Citation Pulmonary tuberculosis, autophagy flux, LC3-I, LC3-II, diagnosis, IFN- $\gamma$

Wahwah SA, Abdulrahman TR, Mankhi AA. Evaluation of autophagy flux LC3 gene expression and serum IFN- $\gamma$ in pulmonary tuberculosis patients. Iraqi JMS. 2020; 18(1): 52-60. doi: 10.22578/IJMS.18.1.8

List of abbreviations: $\mathrm{DC}$ = Dendritic cells, Eis = Enhanced intracellular survival gene, ESAT6 = Early secreted Ag of $6 \mathrm{kDa}, \mathrm{Mtb}=$ Mycobacterium tuberculosis, $\mathrm{TB}=$ Tuberculosis, $\mathrm{Th} 1=\mathrm{T}$ helper $1, \mathrm{Th} 2=$ Thelper 2, miRNAs= MicroRNAs

\section{Introduction}

uberculosis (TB) is an infectious bacterial disease. It is considered to be one of the world's deadliest illnesses (1). The prevalence of TB rod bacilli with the droplet of respiratory secretions is related to coughing or sneezing of the infected individual (2). It is an 
infection that becomes active, which is most frequently occurred in almost $90 \%$ of reported lung cases. Only about 10 percent of people infected with Mycobacterium tuberculosis (Mtb) developed to active TB disease within their lifetime (3). Although, improved and transformative TB diagnostics are still needed to overcome the severe restrictions on older, non-standard and inaccurate techniques currently used in most circumstances ${ }^{(4)}$.

Autophagy is a newly identified innate and adaptive immunity defense upon intracellular pathogens ${ }^{(5)}$. Autophagy can capture and eradicate intracellular microbes, including $\mathrm{Mtb}$ (6). There were much has been reported about the functions of autophagy besides the mechanisms by which the autophagic pathway stimulates the host innate effector response against Mtb infection (7). The phrase "autophagic flux" is utilized to describe the dynamic process of autophagy. In particular, autophagic flux refers to the whole process of autophagy, including autophagosome formation, maturation, fusion with lysosomes, subsequent breakdown and the release of macromolecules back into the cytosol (8). Autophagy aids with antigen processing of intracellular and extracellular element for major histocompatibility complex (MHC) class I and class II presentation for recognition by CD8+ and CD4+ $T$ cells, respectively (9). Predominantly, $\mathrm{T}$ helper 1 (Th1) cytokines stimulate autophagy in order to kill intracellular Mtb ${ }^{(10)}$. Th1 cytokines (IL-2, TNF$\alpha$, and IFN- $\gamma$ ) are recognized as autophagy inducers while T helper 2 (Th2) cytokines (IL-4, IL-5, IL-6, IL-10, and IL-13) and antiinflammatory cytokines are observed as autophagy repressors (11). Mtb has evolved numerous approaches to counteract autophagy. For instance, Mtb Eis (enhanced intracellular survival) gene represses macrophage autophagy and cell death by a reactive oxygen species (ROS)-dependent pathway. In addition, (ESAT6), a significant ESX1-mediated secretory protein, performs a great role in the suppression of late-stage autophagy in human dendritic cells (DCs) ${ }^{(12)}$. The current study aimed to: First, to evaluate the mRNA expression levels of autophagy-related genes of (LC3-1) and (LC3-II) in TB patients through autophagy flux. Second, to evaluate the serum level of IFN- $\gamma$ in pulmonary TB patient groups. And third, to determine the correlation between autophagy- related genes and IFN- $\gamma$.

\section{Methods}

This case control study included fifty pulmonary TB patients were collected from the National Reference Laboratory (NRL) of Tuberculosis Respiratory, Baghdad during the period from January 2019 to September 2019. This study was approved by the Institutional Review Board (IRB) of the College of MedicineAl-Nahrain University, approval code (208).

\section{Study design}

Patients were divided into three groups: multidrug-resistant (MDR) patients group consists of 20 samples, newly diagnosed (ND) group which consists of 20 samples and old case $(\mathrm{OC})$ group with 10 samples. Besides 30 samples of apparently healthy persons as control groups were collected from the Blood Donation Center, Baghdad Medical City.

\section{Inclusion criteria}

Patients with pulmonary TB, age group include eighteen years old and above.

\section{Exclusion criteria}

Patients having an autoimmune disease (Crohn's disease, systemic lupus erythromatosus, multiple sclerosis), central nervous system disease, human immune deficiency dis, patients on radio and chemotherapy, and atypical mycobacteria.

\section{Total RNA purification of LC3-I and LC3-II from} whole blood

Total RNAs were isolated from sample according to the protocol of TRIzol ${ }^{\mathrm{TM}}$ reagent (Thermo Scientific, USA). 
Measuring of mRNA expression level of autophagy-related genes LC3-I and LC3-II by Relative RT Real time polymerase chain reaction (RT-PCR)

The PCR primers were listed in table (1). GoTaq $^{\circledR}$ 1-Step RT-qPCR System combines GoScript $^{\mathrm{TM}}$ Reverse Transcriptase and $\mathrm{GoTaq}^{\circledR}$ qPCR Master Mix (Promega, USA), which enables detection of RNA expression levels using a single-step real-time amplification reaction. Quantitative PCR used for CDNA quantification, this method allows the assessment of the amount of a given sequence present in a sample and quantitatively determine levels of gene expression. Hence, in this study, this method was used to measure levels of gene expression of mRNA for LC3-I and LC3-II target genes. By the use of RT-PCR system software program, the comparative quantification experiment type was selected from the programming window. Then RT-PCR machine was programmed according to the conditions illustrated in table (2). The threshold was set manually at the lowest point of the parallel rise of the logarithmic amplification curve to obtain a cycle threshold (Ct) value for each reaction tube.

Table 1. Primers and its sequences

\begin{tabular}{|c|c|c|}
\hline Primer Name & Primer ID & Sequence \\
\hline \multirow{2}{*}{ LC3-I } & $\mathrm{F}^{*}$ & 5`-GCTACAAGGGTGAGAAGCAGCT-3` \\
\hline & $\mathrm{R}^{* *}$ & 5`CTGGTTCACCAGCAGGAAGAAG-3` \\
\hline \multirow{2}{*}{ LC3-II } & $\mathrm{F}$ & 5`-AATCCCGGTGATAATAGAAC-3` \\
\hline & $\mathrm{R}$ & 5`-TTTCATCCCGAACGTCTCC-3` \\
\hline \multirow{2}{*}{ GAPDH } & $\mathrm{F}$ & 5`AGA AGG CTG GGG CTC ATT TG-3` \\
\hline & $\mathrm{R}$ & $5^{`}$-AGG GGC CAT CCA CAG TCT TC-3` \\
\hline
\end{tabular}

Table 2. Conditions for Real-time PCR run

\begin{tabular}{cccc}
\hline Steps & $\begin{array}{c}\text { Real time PCR program } \\
\text { Temperature }\end{array}$ & Time & Cycle \\
\hline Real time enzyme activation & $37^{\circ} \mathrm{C}$ & $15: 00$ & 1 \\
Initial denaturation & $95^{\circ} \mathrm{C}$ & $10: 00$ & \multirow{2}{*}{40} \\
\hline Denaturation & $95^{\circ} \mathrm{C}$ & 00.20 & \\
Annealing & $60^{\circ} \mathrm{C}$ & 00.20 & \\
Extension & $72{ }^{\circ} \mathrm{C}$ & 00.20 & \\
\hline
\end{tabular}

\section{Gene expression calculation}

The relative expression of a targeted gene was calculated using the formula 2- $\Delta \Delta \mathrm{Ct}$. The folding $=2-\Delta \Delta C T, \Delta \Delta C T=\Delta C T$ Treated $-\Delta C T$ Control, $\Delta C T=C T$ gene $-C T$ House Keeping gene.
Serum IFN- $\gamma$ protein measurement using sandwich Enzyme Linked ImmunoSorbant assay (ELISA)

The current experiment based on utilizing the Sandwich-ELISA principle (elabscience, china). The micro ELISA plate provided in this kit has been pre-coated with an antibody specific to Human IFN- $\gamma$. The optical density (OD value) of each well was determined at once with a 
micro-plate reader set to $450 \mathrm{~nm}$. Finally, for results calculation, four-parameter logistic curve has been plotted on log-log graph paper, with standard concentration on the $\mathrm{x}$-axis and $O D$ values on the $y$-axis figure (1).

\section{Statistical analysis}

The data of the present study were processed using SPSS version 16.0.0, Microsoft Excel 2010, and Graphpad Prism version 7.04. Differences were considered statistically significant at $p<0.05$. Accordingly, the proper statistical tests were used, t-test and ANOVA test were used for parametric data to measure the significance of difference in means taking into account whether variables of analysis sharing different or equal variance. Correlation coefficient tests or, $r$, among variables were used to assess the nature of correlation in terms of positive, negative or indifference.

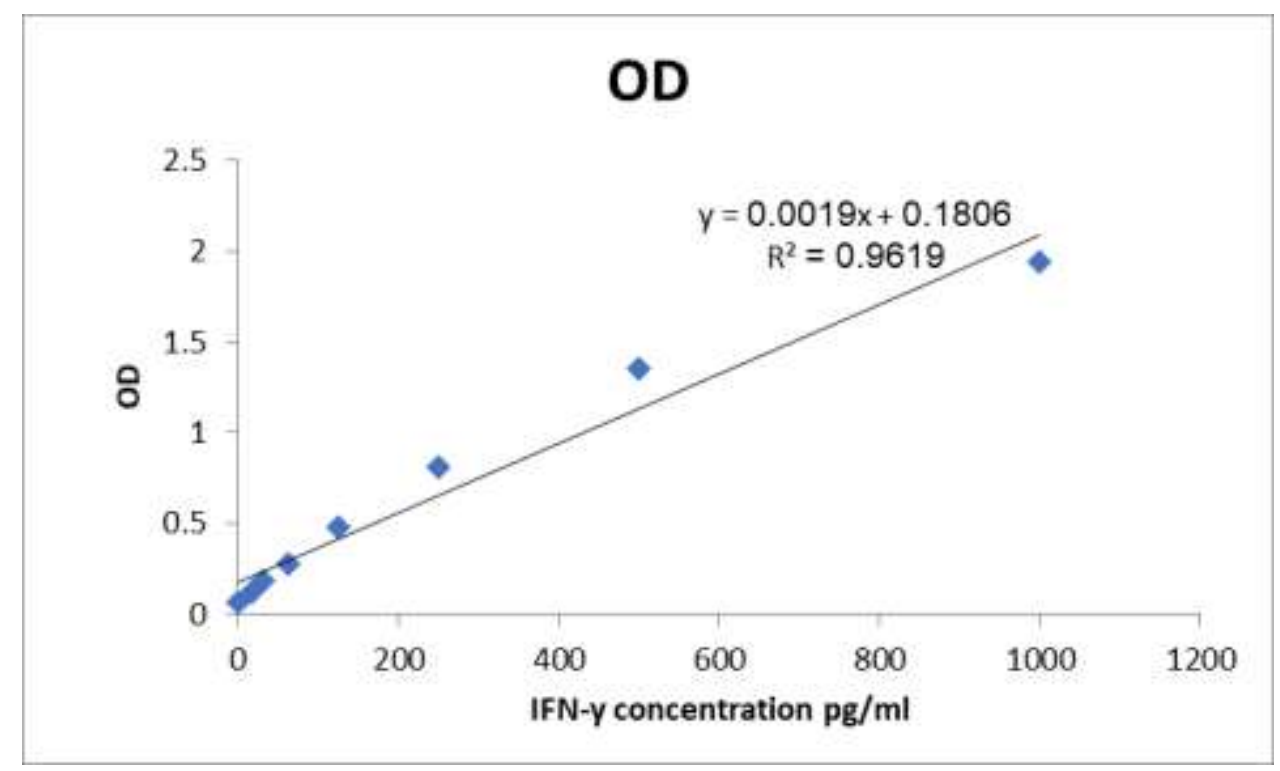

Figure 1. Standard curve of interferon- $-\gamma$

\section{Results}

Regarding the expression level of autophagyrelated genes, the results showed that the mRNA levels of LC3-I were increased in pulmonary TB group than control group, but statically not significant ( $P>0.05)$. There is no statistically significant variation in LC3II folds between PTB patients and the control group (P>0.05) (Table 3).

Furthermore, autophagy flux ratio has been calculated in order to access the entire process of autophagy in pulmonary TB groups. The results have been shown significant decreasing in the ratio of autophagy flux ( $p$ value $=0.027$ ) between pulmonary TB groups and control groups as shown in figure (2). The highest significant decreasing has been shown in newly diagnosed group with ( $p$ value $=0.02$ ), and MDR group with ( $p$ value $=0.05$ ) rather than control group. While in old cases group was nonsignificant ( $p$ value=0.6). The mean \pm SD of autophagy flux in newly diagnosed, MDR, oldcases and control groups were $(0.90 \pm 0.96$, $1.26 \pm 1.38,2.56 \pm 3.62,3.70 \pm 6.48$ ) respectively. Besides the results of the current study showed that IFN- $\gamma$ serum concentration was with highly significant differences $(p=0.0001)$ between PTB groups and control group. IFN- $\gamma$ serum level were significantly increased $(p<0.05)$ in newly diagnosed ND and old cases OC group than the control, while MDR group reach the borderline ( $p$ value $=0.06$ ). Furthermore, among patients' 
groups, there were no significant differences $(P>0.05)$ in the levels of IFN- $\gamma$ between MDR and ND, MDR and $O C$ and ND with OC. As shown in table (4), the serum levels mean $\pm S D$ of MDR, ND, OC and controls were $91.61 \pm 82.04, \quad 1.066 \pm 65.57,90.72 \pm 64.93$, $54.93 \pm 26.61$, respectively.
Further correlations have been made between LC3II gene expression and IFN- $\gamma$. the outcome shows that LC3-II is a dependent factor on IFN$\gamma$ in the MDR TB group with a positive significant correlation $(r=0.54, P=0.013)$ (Table 5 and Figure 3 ).

Table 3. LC3I and LC3II gene expression in TB patients and control groups

\begin{tabular}{|c|c|c|c|c|c|}
\hline & Control vs TB & $\mathbf{N}$ & Mean & Std. Deviation & $P$ value \\
\hline \multirow{8}{*}{$\begin{array}{l}\text { LC3I } \\
\text { folds }\end{array}$} & Control & 30 & 2.12 & 3.27 & \multirow{2}{*}{$0.292^{\mathrm{NS}}$} \\
\hline & TB group & 50 & 24.61 & 115.87 & \\
\hline & Control & 30 & 2.12 & 3.27 & \multirow{2}{*}{$0.671^{\mathrm{NS}}$} \\
\hline & MDR-TB & 20 & 1.76 & 2.33 & \\
\hline & Control & 30 & 2.12 & 3.27 & \multirow{2}{*}{$0.264^{\mathrm{NS}}$} \\
\hline & Newly Diagnosed TB & 20 & 48.11 & 180.14 & \\
\hline & Control & 30 & 2.12 & 3.27 & \multirow{2}{*}{$0.183^{N S}$} \\
\hline & Old TB cases & 10 & 23.31 & 46.86 & \\
\hline \multirow{8}{*}{$\begin{array}{l}\text { LC3II } \\
\text { folds }\end{array}$} & Control & 30 & 2.25 & 2.85 & \multirow{2}{*}{$0.144^{\mathrm{NS}}$} \\
\hline & TB group & 50 & 1.39 & 1.60 & \\
\hline & Control & 30 & 2.25 & 2.85 & \multirow{2}{*}{$0.061^{\mathrm{NS}}$} \\
\hline & MDR-TB & 20 & 1.13 & 1.14 & \\
\hline & Control & 30 & 2.25 & 2.85 & \multirow{2}{*}{$0.382^{\mathrm{NS}}$} \\
\hline & Newly Diagnosed TB & 20 & 1.60 & 1.99 & \\
\hline & Control & 30 & 2.25 & 2.85 & \multirow{2}{*}{$0.442^{\mathrm{NS}}$} \\
\hline & Old TB cases & 10 & 1.51 & 1.58 & \\
\hline
\end{tabular}

NS=none statistical significance $(p>0.05)$ 


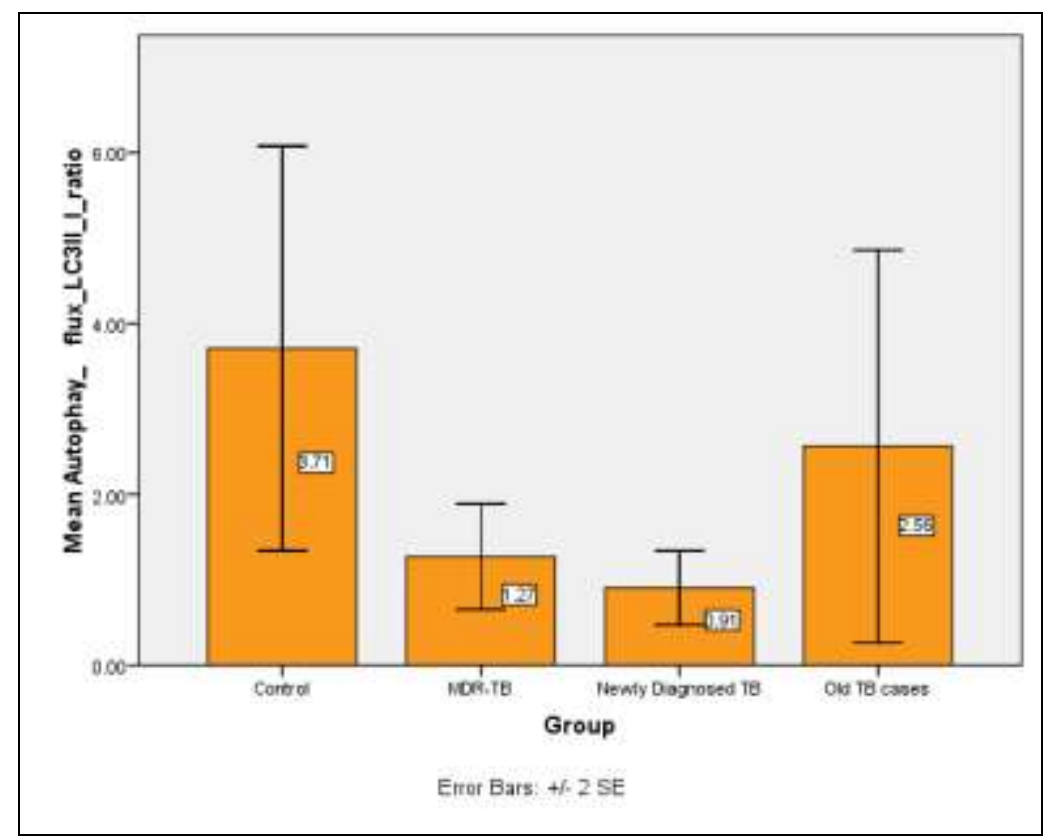

Figure 2. Autophagy flux ratio between pulmonary TB and control groups

Table 4. Serum level of IFN- $\gamma$ in PTB patients and controls

\begin{tabular}{ccccc}
\hline Groups & N & Mean & Std. Deviation & P value \\
\hline Control & 30 & 54.93 & 26.61 & \multirow{2}{*}{$0.0001^{* *}$} \\
TB group & 50 & 97.45 & 71.48 & 0.062 \\
\hline Control & 30 & 54.93 & 26.61 & $0.003^{*}$ \\
MDR-TB & 20 & 91.61 & 82.04 & 26.61 \\
\hline Control & 30 & 54.93 & 65.57 & \multirow{2}{*}{$0.017^{*}$} \\
\hline Newly Diagnosed & 20 & $1.0666 \mathrm{E}$ & 26.61 & \\
\hline Control & 30 & 54.93 & 64.93 & \\
\hline
\end{tabular}

${ }^{*}=$ statistical significance $(p \leq 0.05) * *=$ High statistical significance $(p \leq 0.001)$

Table 5. Correlations between LC3-I, LC3II genes expression and IFN- $\gamma$ in MDR group

\begin{tabular}{cccc}
\hline & & LC3II folds & IFN- $\boldsymbol{\gamma}$ concentration \\
\hline \multirow{2}{*}{ LC3I folds } & Pearson corr. coefficient & 0.342 & -0.034 \\
& Sig. (2-tailed) & 0.140 & 0.887 \\
\hline \multirow{2}{*}{ LC3II folds } & Pearson corr. coefficient & & $0.544^{*}$ \\
& Sig. (2-tailed) & & 0.013 \\
\hline
\end{tabular}




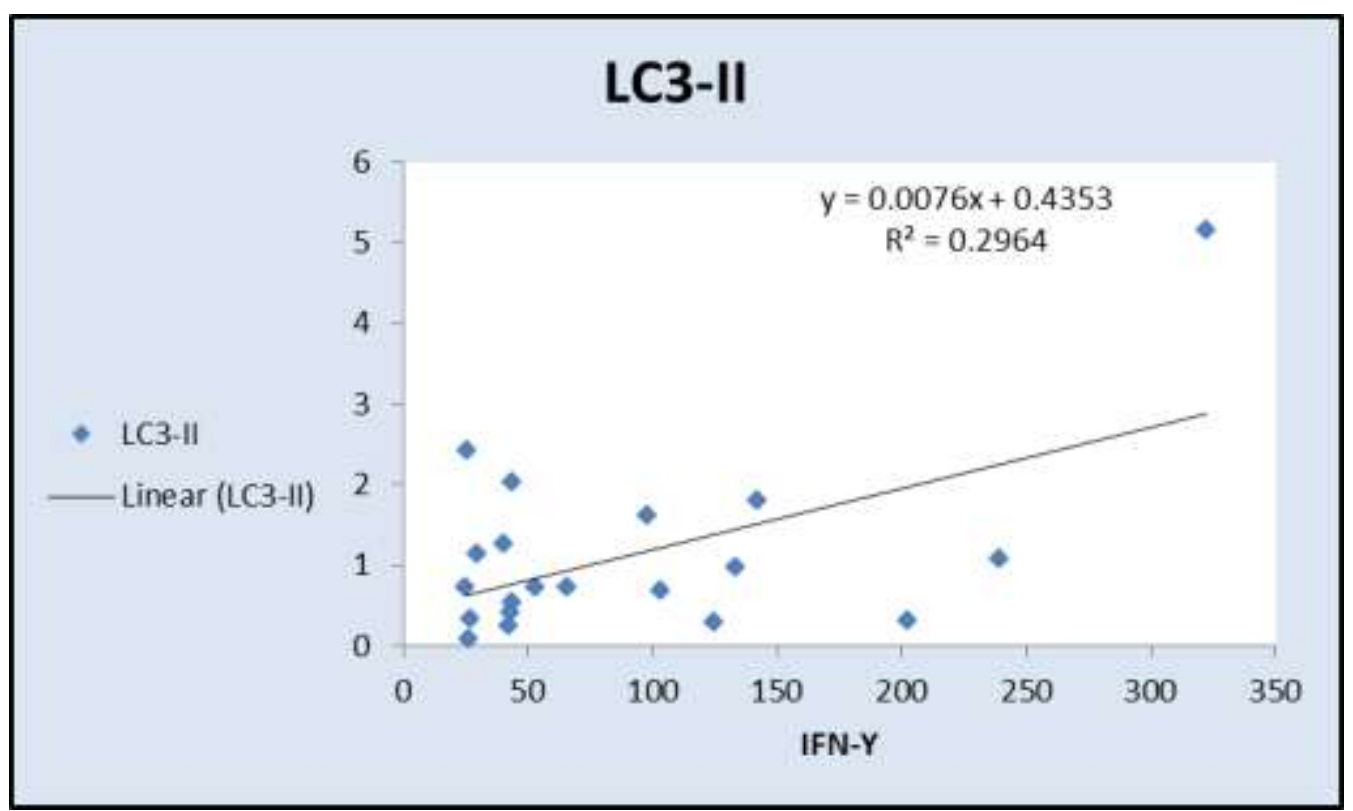

Figure 3. LC3-II is a dependent factor on IFN- $\gamma$ in MDR TB group at correlation coefficient $r=$ $0.544, P=0.013$, and at regression index $\mathrm{R} 2=0.294$ with linear curve equation LC3-II (folds)= $0.0076 x$ LC3-I(folds) +0.4353

\section{Discussion}

Autophagy, a lysosome-dependent degradation process, considered as a crucial innate host defense mechanism in macrophages toward intracellular bacteria, particularly Mtb (16). Autophagy flux refers to the entire process of autophagy, the present study showed block in autophagy flux with significant ( $P$ value $<0.05)$, which may refer to several factors including autophagy modulators such as miRNAs, cytokines, vitamin D3. It has been shown that mycobacterial virulence factors like: PhoP, system 1 (ESX-1) secretion-associated protein $B$ (EspB) and early secretory antigenic target 6 (ESAT-6) are highly linked to immunogenicity and virulence of this organism which could inhibit the process of autophagy. Genetic mutations in humans may cause changes in autophagic flux, also it has been implicated in neurodegenerative diseases and cardiovascular diseases besides cancers ${ }^{(17)}$.

Lambelet et al. in 2018 examined the processed LC3B-II by western blot, together with electron microscopy for autophagosome formation, which have the mainstays for autophagy detection. It has been found that LC3 expression levels can vary markedly between different cell types and in response to different stresses, and there is further concern that over-expression of tagged versions of LC3 to facilitate imaging and detection of autophagy interferes with the process itself (18). Another study worked on autophagy flux in Mtb-infected macrophages and they observed that there is no interesting change in the autophagy flux in macrophages, which disagreed with this study ${ }^{(19)}$.

The findings of serum level of cytokines IFN- $y$ in pulmonary TB of the present study revealed that the serum level of IFN- $\gamma$ was significantly higher $(p=0.0001)$ between PTB groups and control group, this provides new insights into (IFN- $\gamma$ ) as a powerful pro-inflammatory cytokine that plays a major role as biomarker candidates in the pathogenesis and the immune response of pulmonary TB. The findings of the current study in agreement with study by Hussain in 2010 who observed that the levels of interferon-gamma in the blood of tuberculosis patients were significantly higher ( $P$ value $<0.001$ ) in compared to the control group ${ }^{(20)}$. The present study disagreed with AlJubouri et al. (2018), they observed that there were no significant raised in the serum levels of 
IFN- $\gamma$ in patients with pulmonary TB (21). Regulation of cytokine production and autophagy activation seem to be mutually regulated by each other; cytokines regulate autophagy, but the opposite is also true. Furthermore, the present study showed an agreement with Bento et al. (2015) who's studied the correlation between autophagy and inflammation during Mtb infection and observed that IFN- $\nu$ was shown to be an important cytokine in the regulation of mycobacteria clearance by autophagy by Increases production of reactive nitrogen species in macrophages and induces autophagy (22).

As described before, autophagy plays an important role in the host immune response against Mtb and therefore the development of promising autophagy-based therapies including IFN- $\gamma$ to combat TB represents an appealing strategy through enhancing autophagy also increases the efficacy of the only TBprophylactic method available, the BCG vaccine.

\section{Acknowledgement}

The authors would like to acknowledge all participants in this study and staff members in National Reference Laboratory (NRL) of Tuberculosis Respiratory, Baghdad.

\section{Author contribution}

Dr. Wahwah: did the sampling and lab works; Dr. Abdulrahman and Dr. Mankhi supervised the study and participated in its design and interpretation.

\section{Conflict of interest}

Authors declare no conflict of interest.

\section{Funding}

Self-funded.

\section{References}

1. Liang M, Habib Z, Sakamoto K, et al. Mycobacteria and autophagy: many questions and few answers. Curr Issues Mol Biol. 2017; 21: 63-72.

2. Houben EN, Nguyen L, Pieters J. Interaction of pathogenic mycobacteria with the host immune system. Curr Opin Microbiol. 2006; 9(1): 76-85. doi: 10.1016/j.mib.2005.12.014.
3. Bloom BR, Atun $\mathrm{R}$, Cohen $\mathrm{T}$, el al. Tuberculosis. In: Holmes KK, Bertozzi S, Bloom BR, et al. (eds) Major infectious diseases. $3^{\text {rd }}$ ed. International Bank for Reconstruction and Development / The World Bank. 2017.

4. Fauci AS, Eisinger RW. Perspective piece Reimagining the research approach to tuberculosis. Am J Trop Med Hyg. 2018; 98(3): 650-2. doi: 10.4269/ajtmh.170999.

5. Vergne I, Singh S, Roberts E, et al. Autophagy in immune defense against Mycobacterium tuberculosis. Autophagy. 2006; 2(3): 175-8. doi: 10.4161/auto.2830.

6. Castillo EF, Dekonenko A, Arko-Mensah J, et al. Autophagy protects against active tuberculosis by suppressing bacterial burden and inflammation. Proc Natl Acad Sci USA. 2012; 109(46): E3168-76. doi: 10.1073/pnas.1210500109.

7. Jo EK. Autophagy as an innate defense against mycobacteria. Pathog Dis. 2013; 67(2): 108-18. doi: 10.1111/2049-632X.12023.

8. Zhang $X J$, Chen $S$, Huang $K X$, et al. Why should autophagic flux be assessed? Acta Pharmacol Sin. 2013; 34(5): 595-9. doi: 10.1038/aps.2012.184.

9. Schmid D, Münz C. Innate and adaptive immunity through autophagy. Immunity. 2007; 27(1): 11-21. doi: 10.1016/j.immuni.2007.07.004.

10.Zarelli VE, Giai C, Colombo M. Interaction of Mycobacterium tuberculosis with the host cells: a focus in the molecular mechanism involved in trafficking and autophagy. In: Tuberculosis (ebook). www.smgebooks.com. 2018. p. 1-16. URI: http://hdl.handle.net/11336/99179.

11. Harris J. Autophagy and cytokines. Cytokine. 2011 Nov; 56(2): 140-4. doi: 10.1016/j.cyto.2011.08.022.

12. Paik S, Kim JK, Chung $C$, et al. Autophagy: A new strategy for host-directed therapy of tuberculosis. Virulence. 2019 Dec; 10(1): 448-59. doi: 10.1080/21505594.2018.1536598.

13. Microtubule associated protein 1 light chain 3 beta [ Homo sapiens (human)]. Gene ID: 81631, NCBI(2020). https://www.ncbi.nlm.nih.gov/gene/?term=NM_022 818.

14. Ma $Y$, Zhang $Y$, Zhao $Y$, et al. Expression of autophagy-related genes in cerebrospinal fluid of patients with tuberculous meningitis. Exp Ther Med. 2018; 15(6): 4671-6. doi: 10.3892/etm.2018.5999.

15. Yang SL, Wang JJ, Chen M, et al. Pioglitazone Use and Risk of Bladder Cancer: an in vitro study. Int J Med Sci. 2018; 15(3): 228-37. doi: 10.7150/ijms.22408.

16. Weiss G, Schaible UE. Macrophage defense mechanisms against intracellular bacteria. Immunol Rev. 2015; 264(1): 182-203. doi: 10.1111/imr.12266.

17. Youssefi M, Eslami M, Karbalaei M, et al. Autophagy as one of the most important strategies for the treatment of tuberculosis; Mini-review. Rev Clin Med. 2019; 6(4): 135-9. doi: 10.22038/RCM.2019.14176.

18. Lambelet $M$, Terra LF, Fukaya $M$, et al. Dysfunctional autophagy following exposure to pro-inflammatory 
cytokines contributes to pancreatic $\beta$-cell apoptosis. Cell Death Dis. 2018; 9(2): 96. doi: 10.1038/s41419017-0121-5.

19. Chandra $P$, Kumar D. Selective autophagy gets more selective: Uncoupling of autophagy flux and xenophagy flux in Mycobacterium tuberculosisinfected macrophages. Autophagy. 2016; 12(3): 6089. doi: 10.1080/15548627.2016.1139263.

20. Hussain S, Afzal N, Javaid $K$, et al. Level of interferon gamma in the blood of tuberculosis patients. Iran J Immunol. 2010; 7(4): 240-6.

21. Al-Jubouri AMS, Al-Saadi MAK, Al-Mosawi HMA. Estimation of some immunological factors in pulmonary tuberculosis patients. J Univ Babylon Pure Appl Sci. 2018; 26(9): 39-49.

22. Bento CF, Empadinhas N, Mendes V. Autophagy in the fight against tuberculosis. DNA Cell Biol. 2015 Apr; 34(4): 228-42. doi: 10.1089/dna.2014.2745.

\section{Correspondence to Sarah A. Wahwah}

E-mail: sarah_salam@yahoo.com

Received Jul. $7^{\text {th }} 2020$

Accepted Sep. $1^{\text {st }} 2020$ 